\title{
Knowledge Revolution through Online Interactive Platform: International Microsurgery Club
}

\author{
Tommy Nai-Jen Chang, MD*
}

Department of Plastic and Reconstructive Surgery, Chang Gung Memorial Hospital, Linkou Medical Center and Chang Gung Medical College and Chang Gung University, Taoyuan, Taiwan

\section{Introduction}

The learning habit has been changing gradually in the past few decades, from paper products to $3 \mathrm{C}$ products. Nowadays people learn almost everything from different kinds of $3 \mathrm{C}$ products, especially when the Internet is connected. The professional field is no exception. The presence of online learning resources has grown tremendously in recent years, which provides an excellent and easy accessibility for knowledge sharing. Papers and textbooks have shifted to e-published editions instead of the traditional printing paper editions. Millions of photos and video demonstrations can also be viewed online via Google, YouTube, and other search engines. However, these resources are mostly one-way communications. The interactive communication can target the questions so that the learning process can be much more efficient. However, the development of the online interactive platform is still far behind the requirement, and hence, generally, the people still depend on traditional ways, such as attending the conference or consulting the experts to get the idea.

The online platform in the medical field is a new format of the interactive learning. The idea is straightforward, and the setup is easy, but the maintenance is tough. It requires some skilled users or admins to upload the original educational materials periodically and maintain the group continuously. In the very beginning, the platform was usually "closed" (physician-only and password protected) type, such as doctors.net.uk in the UK, Doximity in USA, and Dxy in China. However, subsequently, the platform changed to open public channels, such as Facebook, Twitter, and LinkedIn $[1,2]$. These open platforms are more efficient for learning since their set up is more attractive, and the system reminds you to update periodically [3].

International Microsurgery Club (IMC), initiated on May 6, 2016, is a closed, invitation-only group on the social media platform base on Facebook. The primary goal of this group is to provide a convenient forum for discussion of challenging cases, and sharing of valuable resources and opportunities for research collaboration for global microsurgeons. Until now (July 2017), the membership of IMC has reached more than 6000 and it has become one of the largest online microsurgery platforms in the world. We believe that the online platform brings forth a kind of knowledge revolution because its feasibility and convenience may gradually replace many academic activities in the future. From our experience,

*Correspondence: Tommy Nai-Jen Chang, MD

Department of Plastic and Reconstructive Surgery, Chang Gung Memorial Hospital, Linkou Medical Center, Taoyuan, Taiwan.

Email: tommynjchang@yahoo.com.tw

Received: July 11, 2017; Accepted: July 21, 2017; Published: July 28, 2017

International Microsurgery Journal. 2017;1(2):1

DOI: $10.24983 /$ scitemed.imj.2017.00023

Copyright $(2017$ The Author. This is an open-access article distributed under the terms of the Creative Commons Attribution 4.0 International License (CC-BY). we have identified several advantages of the interactive online platform, as summarized below.

\section{To get the real answer throughout the online brainstorm}

When we learn from the textbook or paper, we get the limited knowledge provided by the author. The discussion on the interactive platform makes the learning more flexible and close to the actual condition. For example, from literature, the indications of the Mackinnon/Oberlin-II double fascicular transfer (DFT) for elbow flexion in acute brachial plexus injury were set within six months, at most 12 months. However, during the online discussion, few authors have presented their experiences that this operation can extend to the patients 20 months after the injury, but they have never published it. From our experience, in patients who received proximal neurotization (nerve transfer in the neck level) for elbow flexion, the denervated time of the biceps/brachialis muscle was around 20 months in total ( 6 months before the operation +18 months after the operation), and still it was possible to achieve the powerful elbow flexion. By online brainstorm, we thought this idea was reasonable and applicable, and also possible to apply to the clinical practice in the future.

\section{Easy to find the experts in the same field globally}

For example, peripheral nerve surgeons belong to a small group in microsurgery, and traditionally the people interact with each other during the scientific meetings. However, with the prevalence of Internet, and the inclusion of more and more experts into the group, it becomes much easier to find the people with the same interest, which helps each other in their particular fields.

\section{Identify the "no-name heroes"}

Traditionally the well-known experts were defined as those people who had vast experience for publication and were frequently present in the conferences. The definition may have the bias because still there are lots of surgeons performing well, though they don't attend the scientific activities so frequently. However, through the online interactive platform, they can easily present their masterpieces in an accessible format. In IMC we have already identified many "no-name heroes" who are really great surprise and treasure for the global microsurgeons.

\section{All the activities are free of charge}

Compared with the current conference and journal system, one of the best advantages is that everything throughout IMC is free. This makes all the activities very comfortable, and this is highly valuable for the microsurgeons, especially for those from relatively low-income countries.

The discussion is always ongoing without any time constraint Everything posted in the online interactive platform can be discussed continuously without any time limitation, and can be traced easily since everything is well organized. 


\section{Editorial}

\section{Social media starts to move the real world}

It has the power for developing relationships and networks within a specialty. From our observation, the members not only involve in online discussions, but also develop more interaction in the real world. They either cooperate in paper writing or visit the masters in the meeting or their units. Some power users of IMC have more than 100 new Facebook friends from IMC within a period of one year.

\section{Future}

No one can deny the power of Internet. No matter you like it or not, everyone will be on board finally, just like nowadays everyone uses emails to communicate with each other in seconds, instead of sending hard copy of letters by post as they did twenty years ago. Some prophecies are worthy of verifying in the future.

The online interactive platform will become more and more popular and play more important roles in the medical education

More and more related resources such as conference information and related product information will be compiled. Some small groups may either shut down or integrate into few big groups. By the development of the Facebook, videos uploading will become more and easier, which will be beneficial for the learning process.

\section{The online meeting system will replace some conferences}

Before the prevalence of the Internet, attending the conference was the only way to interact with the international masters. However, it was timeconsuming and involved huge expenses, which restricted the activities of the microsurgeons. The interactive platforms provide the opportunity for discussion, completely free of charge, and without any time constraint. Although nowadays the online meeting system is still in the booming stage, the quality of videos, and the interactive system between the speakers and the audiences will be upgraded and improved soon. The convenience and economy of the online meeting will amaze the current conference system. The conferences need to provide something that cannot be replaced - such as hands-on course, to keep the advantage.

\section{The publications will shift to easier format gradually}

Videos are always more attractive than photos and lengthy paragraphs. It is not easy to finish a 3000-word paper to learn a technique or get an idea.
More and more journals have started the video section but are still not technically matured. However, by the habit of reading, the video with short paragraph will be a major format of publication in the future.

The copyright issue will be a troublesome problem that cannot be solved, and the journal system will eventually shift to open access format

Nowadays, most of the journals are still non-open accessed and charge to the institutions. However, some websites such as ResearchGate and Sci-Hub release most of the manuscripts, which make the journals initiate to charge the author and shift to open access (mainly new journals).4 All the open access papers allow the reader to view online without any charge. Although the legitimacy of the ResearchGate and Sci-Hub still remains uncertain, more and more users support them, and eventually, the copyright problem will be an unresolved issue, and all the information from the journals will be released online.

\section{Conclusion}

One of my mentors, Dr. Wei F Chen (U.S.A.), concludes IMC as "A Fantastic platform for learning, professional development, and camaraderie. It's all just a few clicks away!" Now is 2017, and this is only the beginning of social media's involvement in the medical education. In the future, we will recognize that its power is unlimited.

\section{Article Information}

Conflict of Interest Disclosures: None

Funding: None

\section{Reference}

1. McDonald JJ, Bisset C, Coleman MG, et al. Contemporary use of social media by consultant colorectal surgeons. Colorectal Disease. 2015;17(2):165-171.

2. Branford OA, Kamali P, Rohrich RJ, et al. \#PlasticSurgery. Plast Reconstr Surg. 2016;138(6):1354-1365.

3. Salvatore TS, Luigi ML. Social networking and plastic surgery education: running international plastic surgery. Arch Plast Surg. 2014; 41(4):446.

4. Lewis DW. The inevitability of open access. College \& Research Libraries. 2012;73(5):493-506 